\title{
Contribuições filosóficas e sociológicas sobre a infância
}

\section{Vera Lúcia Chacon Valença*}

\section{Resumo}

O fio condutor deste artigo encontra-se em algumas contribuiçôes filosóficas e sociológicas sobre a história da infância e suas repercussōes nas relações educativas. Uma revisão teórica sobre a história da infância fez sobressair, na antiguidade, uma infância excluída, abandonada, sem afeto; posteriormente, na modernidade, uma infância constituída por um "outro-criança" com direitos jurídicos reconhecidos, portanto, um "outro" igual, mas diferente; e a infância da contemporaneidade representada por um "outro-criança" diferente, mas igual em direitos. Dessa forma, o desafio para os educadores atuais consiste em saber relacionar-se com a alteridade paradoxal da criança, diferente e igual em direitos, exercendo uma hierarquia horizontal que possibilite a construção da identidade e a busca de autonomia das crianças.

Palavras-chave: Infância. Contribuiçóes teóricas. Repercussóes educativas.

* Doutora em Psicologia Aplicada pela Université Paris Descartes, França. Professora da Universidade do Sul de Santa Catarina (UNISUL). 
As reflexôes aqui apresentadas surgiram a partir da leitura do livro La liberation des enfants, do filósofo Renaut (2002). Às contribuiçóes do autor juntaram-se outras de autores tais como: Michel Foucault (2008), Hannah Arendt (1997), William Corsaro (2011), Cléopâtre Montandon (1997, 2004, 2005, 2006), Gastón Mialaret (2013), entre outros.

Há uma concordância de todos quanto à complexidade da infância expressa, por exemplo, por Chombart de Lauwe (1976), que afirma que a criança precisa ser considerada não apenas como um indivíduo, um caso psicológico, um membro de um meio familiar, mas alguém pertencente a uma classe social, a infância. Vista sob esse prisma, deduz-se a necessidade de estudá-la sob várias perspectivas, sendo mesmo sugerido que o ideal é realizar uma abordagem interdisciplinar. Investigada pela psicologia, antropologia, ciências sociais, entre outros, neste texto foram ressaltadas, porém, algumas contribuições da sociologia da infância e da filosofia que colaboraram para algumas reflexôes que dizem respeito às relaçôes crianças-adultos.

Percebidas pelo filósofo Renaut (2002) como os "outros iguais e dessemelhantes", e por Corsaro (2011, p. 15) como "agentes sociais ativos e criativos que produzem suas próprias e exclusivas culturas infantis, enquanto simultaneamente, contribuem para a produção das sociedades dos adultos", as crianças constituem uma categoria social, a infância que é considerada o "período socialmente construído em que as crianças vivem suas vidas”. No entanto, elas não a vivem isoladamente. Elas participam da criação da cultura da infância e daquela dos adultos "por meio da produção e participação nas rotinas (CORSARO, 2011, p. 128). Como, então, elas vivem suas rotinas convivendo com outras crianças e com os adultos? Com seus pares constituem as denominadas culturas de pares definidas como "um conjunto estável de atividades ou rotinas, artefatos, valores e preocupaçóes, que as crianças produzem e compartilham em interação com as demais" (CORSARO, 2011, p. 128).

No que diz respeito à participação delas, como membros do mundo adulto, a rotina adulto-criança, nem sempre ocorre de forma tranquila, o que gera, tanto nelas quanto nos adultos, ambiguidades, inseguranças, ansiedade e conflitos. $\mathrm{E}$ isso se entende exatamente quando se consideram as diferenças entre elas e os adultos: elas mais dependentes, em formação, embora existentes, já no presente; os adultos necessitando adequar-se ao exercício de uma autoridade negociável, uma necessidade de aprender a conviver com um outro táo paradoxal: tão diferente e tão semelhante, em direitos jurídicos.

Os adultos se interrogam: como lidar, no dia a dia, com uma alteridade táo contraditória? Reconhecem que a criança precisa de proteção. Em que consistiria sua liberdade, autonomia e identidade como sujeito? Ao mesmo tempo eles precisam 
exercer sua autoridade, recompor o exercício de poder, desmantelado desde a modernidade. Essas questóes repercutem nas relações educativas adulto-criança, razão do interesse em tentar buscar algumas respostas para elas.

\section{A história das representações da infância: uma rápida incursão}

Sobre a história da infância, numa perspectiva filosófica, Renaut (2002) destaca a existência, nas sociedades tradicionais, de um sentimento arcaico, superficial da infância. Não existia afeto entre adultos e crianças que não eram consideradas como tendo uma identidade própria, particular. Exemplo disso era a reação dos adultos face à morte de algumas delas: o pensamento dirigia-se para a sua substituiçáo por outras crianças que nasceriam. Nos cemitérios não existiam tumbas individuais para elas. A missão educativa consistia em conservar os bens materiais e, eventualmente, proteger suas vidas.

$\mathrm{Na}$ Idade Média, a criança era percebida como dependente. Contudo, ela aparecia misturada aos adultos nas atividades, participando das cerimônias, reuniôes familiares e sociais. Utilizava os mesmos jogos com eles, não sendo feitas distinçôes entre aquilo que passaria a ser outra categoria social. Entre os gregos e romanos a educação era concebida como iniciação: o percurso da vida era fixado a priori, antes mesmo do nascimento. Buscava-se perpetuar a linhagem: entendia-se que as crianças, em funçáo de sua natureza e dos seus ascendentes, deveriam preservar a ordem imutável do mundo. A educação tinha por função resguardar o comportamento, as tradiçóes do passado.

$\mathrm{Na}$ modernidade, e sob a égide da democratização, os valores da liberdade e da igualdade de direitos passaram a ser determinantes do processo educativo. A alteridade do "outro-criança", com suas diferenças naturais e também sociais e culturais se confrontaram com o mundo do adulto (AMORIM, 2001). Surgem, entretanto, o isolamento da escola com relação à sociedade e com ele a atribuição a essa instituição de normatizar/uniformizar as crianças: elas passaram a ser hierarquizadas quanto a algumas características pessoais, como aptidóes, resultados de exames etc. As crianças começaram a ser rotuladas muito frequentemente pelos adultos, que esquecem, às vezes, que elas reagem como um "eu”, e tornar-se-ão um "eu” (RENAUT, 2002). Partindo-se do pressuposto de que todos os seres humanos sáo iguais de direito ou em direito, a possibilidade de sufocar a alteridade da criança culminou com o retraimento durável da infância da comunidade dos "iguais", assim considerados nas sociedades 
democráticas. Sendo assim, como é discutida a educação a partir da crise estabelecida na modernidade?

$\mathrm{Na}$ modernidade exacerbou-se uma crise na educação decorrente, entre outros fatores, e segundo Hannah Arendt (1997), do desmantelamento da figura de autoridade. Conforme lembra autora, a autoridade "sempre exige obediência, ela é comumente confundida com algum poder ou violência” (ARENDT, 1997, p. 129). Todavia, a autoridade pode ser exercida sem a utilização de meios externos de coerção. Entende Arendt (1997, p. 129) que "onde a força é usada, a autoridade em si mesmo fracassou".

Historicamente foram sendo perdidas algumas tradiçóes, como a religião, e finalmente a autoridade foi desaparecendo. A perda da permanência e da segurança do mundo, decorrente da perda da autoridade, não acarreta, pelo menos não necessariamente, "a perda da capacidade humana de construir, preservar e cuidar de um mundo que nos pode sobreviver e permanecer um lugar adequado à vida para os que vêm depois", como explica Arendt (1997, p. 132). Para ela, entre o que manda e o que obedece, o que há em comum é a hierarquia e a liberdade, esta, por sua vez, estaria associada à presença da soberania. Nessa discussáo, como ficaria a autonomia da criança, considerando que o poder será exercido pelo adulto, de quem ela depende? Poderia ela experimentar algum tipo de "autonomia"?

Levando-se em conta essa "nova" criança, na contemporaneidade as relaçôes educativas precisam ter como fio condutor um aprendizado: o de conviver com o diferente, com as especificidades comportamentais das crianças. E a questâo é: como estabelecer nelas relaçôes hierárquicas? Como recompor a figura de autoridade em face de outro "diferente" e "igual"? O que se entende por educação, afinal?

\section{A educação-socialização: algumas contribuições e reflexões}

Muitos significados envolvem o termo "educação". Mialaret (2013, p. 24) assegura que se trata de um termo polivalente que traduz quatro significados:

a) "Evoca uma instituição social, que possui estruturas de funcionamento, apresentando algumas delas sistemas mais ou menos difusos, alguns dos quais completam a função dos ministérios de Educação, quais sejam: formação de adultos, animaçōes culturais. Envolve também sistemas informais, tais como rádio, televisão, internet etc.; 
b) significa o resultado de uma ação, ou seja, os produtos dela resultantes, por exemplo: educação popular, oposta à erudita;

c) está associado a um determinado conteúdo;

d) diz respeito ao processo resultante da comunicação entre seres humanos e que envolve trocas e modificaçóes recíprocas decorrentes das relaçóes estabelecidas entre eles". (MIALARET, 2013, p. 24).

É sobre esse último significado que recai o interesse da autora deste texto, ao que Cléopâtre Montandon (1997, p. 17) refere-se pela expressão "educação-socialização", que considera que a educação faz parte da socialização, estando a educação "sobretudo associada a um projeto, a socialização compreende aprendizagens que se produzem além do projeto, sem que ela tinha tido aprendizagens intencionais". A fronteira entre os dois processos é muito tênue, sendo, às vezes, difícil distingui-los.

A educação das crianças despertou muito interesse entre os gregos que estiveram sensíveis às influências causadas por elas sobre seus pais. Na Idade Média, no Ocidente, cabia aos adultos libertá-las do pecado original. Só no século XVII, a partir de Rousseau, a natureza do educando passou a ser identificada como não sendo tão má quanto se pensava. A ocupação de lugar central da criança, na sociedade dos adultos, ficou mais evidente no período da industrialização e de outras transformaçóes da sociedade: a infância representava "autenticidade e a contestação da sociedade dos adultos" (MONTANDON, 1997, p. 14). Assim, ia sendo delineado o perfil de uma criança visível, ativa, o "outro" lado da relação: criança-adulto.

O interesse pela criança envolveu, no século XIX, higienistas, filantropos, que dela passaram a se ocupar. No último quarto do século XIX, foi instituída a escolaridade obrigatória, ao mesmo tempo em que os movimentos de proteção à infância, medicalização etc., intensificaram-se. $\mathrm{O}$ objetivo era cuidar dela: tudo era feito para o "bem das crianças", assim o adulto ia definindo e controlando a sua socialização. Também alguns pintores foram sensíveis ao mundo das crianças, entre eles destacaramse: Matisse, Kandiinsky, Klee, Picasso, Miró, entre outros. Tudo isso ia afirmando a existência do "outro-criança” e chamando atenção para a sua educação-socialização.

No meio do século XX, a psicologia do desenvolvimento (Piaget, Walon e Vygotsky), deu suporte às práticas pedagógicas. Além disso, antropólogos (Ruth Benedict e Margaret Mead), psicanalistas (Freud e Françoise Dolto) e historiadores (Philippe Ariès) acrescentaram teorias, quadros conceituais para os que desejavam entender a infância e dedicar-se à sua educação-socialização.

Foucault (2008), o filósofo da exclusão, evidenciou as dificuldades que os adultos demonstraram, inclusive na modernidade democrática, em lidar com as 
diferenças ou alteridade das crianças. Na relação adulto-criança, embora elas tivessem sido consideradas juridicamente como tendo os mesmos direitos, permaneciam sendo consideradas como incapazes, dada a sua especificidade. $\mathrm{O}$ autor entendeu, a partir disso, que os adultos recorreram a normas disciplinares que foram aplicadas às crianças, tanto ao corpo quanto ao espírito. Na modernidade, então, a criança foi inscrita no sistema de vigilância e normalizaçáo. Portanto, a modernidade reintroduziu, assim, uma educação-socialização em que a punição, a humilhação e a desclassificação do "outro-diferente" era praticada. Submetida ao adulto, que tudo controlava para o "seu bem”, pouco espaço restava à criança. A regra era disciplinar, normatizar, avaliar, "tornar iguais" os diferentes. Para isso, a escola avaliava o tempo todo: rotulava, classificava, repreendia os que se comportavam diferentemente, estabelecendo certo comportamento padrão. As relaçôes educativas tinham por base a repressão e a exclusão, e a família seguia as orientaçôes escolares, mas isso ocorria sempre "para o bem das crianças": se elas não entendiam as puniçóes no momento, com certeza conseguiriam, no futuro, compreendê-las.

$\mathrm{Na}$ contemporaneidade, porém, a criança deixou de ser considerada unicamente um objeto, passando a ser importante agora observá-la como ator principal de sua socialização. A sociologia da infância veio somar suas contribuiçôes àquelas de outros campos do saber. Admitir que a criança "é de uma essência diferente, náo responsável, um ser incompleto que tem que aprender tudo com o adulto e que deve se adaptar aos projetos dos adultos, não é a mesma coisa que pensar que ela é capaz de raciocinar, ter responsabilidades, direitos e deveres" (MONTANDON, 1997, p. 19). Considerar a criança como uma construção nova, não apenas cópia fiel dos adultos, implica admitir a relação educativa como sendo uma relação de reciprocidade. Interessa, então, saber o que fazem as crianças daquilo que ensinam os adultos (MONTANDON, 1997, 2004). E o que os adultos aprendem com elas?

\section{Educação, autoridade e autonomia}

Como vem sendo destacado, quando o "outro" da relação é a criança as dificuldades surgem e estão associadas à questôes naturais, além de culturais e sociais. Depois de um período de retraimento da infância em razão das sociedades modernas terem dificuldade de inscrever sua alteridade no registro da igualdade - devido à dependência e imaturidade infantis -, constatam-se, na contemporaneidade, algumas transformaçôes. Atualmente, busca-se estabelecer um equilíbrio mais estável, do que aquele ocorrido na modernidade, entre identidade de direitos e o fato de a criança permanecer com limitaçóes para assumir sozinha sua liberdade e autonomia. 
A questão encaminha-se no sentido da aceitação, como valor a ser respeitado, da dessemelhança das crianças com relação aos adultos. Isso implica uma tomada de consciência por parte dos adultos a respeito da identidade humana das crianças ao mesmo tempo em que eles precisam incorporar a experiência de uma hierarquia diferenciada, ou seja, desempenhar o poder/autoridade de modo mais flexível, menos autoritário do que o faziam anteriormente. Isso significa, pelo menos, aprender a "mandar" e exercer uma autoridade horizontal em substituiçáo àquela vertical que outrora predominava.

A criança possui duplo aspecto para o educador: é um novo num mundo que lhe é estranho e ela está em processo de formação (ARENDT, 1997). Por apresentar essa duplicidade, ela impóe ao educador também um relacionamento duplo: auxiliá-la a se relacionar com o mundo e com a vida. Para isso, ela necessita de proteção, suporte e ensinamentos. É imprescindível que experimente situaçóes de desafios cotidianos e aprenda com os adultos, tendo a liberdade de interpretar, a seu modo, aquilo que lhes foi transmitido nos espaços familiar e escolar, além da convivência com seus pares. Porém, as interaçóes são indispensáveis para garantir sua evolução, que ocorreria em círculos concêntricos no meio dos quais estaria a família. Contudo, a criança precisa exercer o direito de ser ela mesma diante dos outros, e o educador teria interesse em saber o que ela faz daquilo que lhe foi transmitido, isto é, como ela interpreta o que lhe foi ensinado.

A emancipação das crianças vem sendo um processo longo e exige uma mudança de comportamento dos educadores que precisam executar uma mediaçáo entre elas e as pessoas e entre elas e o mundo de modo geral, sabendo que a autoridade exercida por um adulto, corretamente, é mais salutar do que aquela que, porventura, venha a ser desenvolvida por um grupo, mesmo de pares. O peso da pressão de um grupo costuma ser mais tirânico, lembra Arendt (1997). Isso, bem entendido, se o educador não for repressivo nem exclusivo (RENAUT, 2002).

Uma postura crítica, consciente dos educadores, sobre como estabelecer uma relaçáo saudável com o "outro-criança”, torna-se indispensável para o estabelecimento de uma nova configuração educativa. Ela deverá ser fundamentada numa autoridade hierárquica horizontal, única, compatível com uma criança protagonista. Essa postura do adulto viabilizaria as expressóes das crianças quanto às suas necessidades, aspiraçóes, enfim. possibilitando-lhes liberdade de expressão e ação, o que supõe diálogo construído entre ela e o educador.

Considerando que a realização de ações está ligada à autonomia, em quais experiências das crianças elas expressariam autonomia? Será que hoje as crianças são mais autônomas do que antes? A partir de quais argumentos poder-se-ia afirmar isso? 
Nas relaçóes educativas, sejam de pais e filhos, sejam de professores e alunos, como podem se estabelecer convívios equilibrados entre dois seres iguais em direitos e muito diferentes em características/comportamentos? E como pode ser estabelecida a hierarquia, o poder a ser exercido, entendendo as crianças como seres "livres"?

Influenciada pela família, escola e seus pares, a criança exerce experiências de autonomia. $\mathrm{Na} \mathrm{A}$ criança da atualidade já não pode ser marginalizada como antes, porque os adultos náo as consideram mais como "um potencial e ameaça para as sociedades atuais e futuras" (CORSARO, 2011, p. 18). Elas realizam uma reprodução interpretativa, não se limitando "a internalizar a sociedade e a cultura, mas contribuem ativamente para a produção e mudanças culturais”, é o que elucida Corsaro (2011, p. 31-32). Tal reprodução tem por base um novo modelo de desenvolvimento: o da teia global, representado graficamente por uma forma espiralada que demonstra, através dos seus raios, "uma faixa de locais ou campos que compóem, ilustram os diversos locais em que o comportamento ou interação institucional ocorre" (CORSARO, 2011, p. 39).

No centro da espiral encontra-se a família de origem. Integrando duas culturas interligadas - a do adulto e a das crianças -, a criança precisa ser estudada interagindo tanto com seus pares quanto com os adultos.

As relaçóes crianças-adultos póem em jogo discussóes a respeito de sua educação-socialização, visando, particularmente, ao valor da diferença (de idade, mas também, de gênero e cultura), conforme já explicitado anteriormente. O interesse dos educadores é o de tentar equilibrar a tensão criada entre os dois polos, criança e adulto, que culmina, muitas vezes de forma desastrada, à custa da asfixia da alteridade da criança. Entre os modernos, a questáo de inscrever a infância no registro da igualdade esbarrava na sua dependência e imaturidade, a declaração dos seus direitos a tornava igual; na contemporaneidade, assumida a sua diferença, era possível destacar suas necessidades reais e respeitar sua espontaneidade e criatividade. Embora as diferenças entre adultos e crianças possam ser consideradas como um valor em si mesmo, como propôe Renaut (2002), não é tâo fácil assim conviver com essa realidade no dia a dia. Não tem sido tão simples assim falar de autonomia das crianças e interroga-se a respeito sobre como o adulto exercerá sua autoridade/poder. Tendo suas opiniôes, sobre educaçáo e autonomia, ouvidas por Cléopâtre Montandon (1997, 2004), o que elas acrescentam à reflexão que os educadores podem realizar sobre o assunto?

Montandon (1997, 2004) buscou preencher algumas lacunas investigando o que pensam as crianças sobre sua educação e sobre sua autonomia (MONTANDON; LONGCHAMP, 2007). Na primeira pesquisa, ela realizou uma investigação com 67 crianças de 11-12 anos dos dois sexos, frequentando as classes da sexta série primária de 
escola pública, em Genebra (MONTADON, 1997, 2004). As crianças foram submetidas à entrevistas que contemplaram os seguintes componentes: as representaçôes que elas tinham de suas socializaçôes, as emoçóes experimentadas sobre o processo educativo e as açôes nas quais se engajavam.

Em linhas gerais, sobre as práticas dos seus educadores, as crianças esperam dos pais um maior suporte afetivo, e dos professores, mais escuta, gentileza e compreensão. As qualidades expressivas foram mais valorizadas que as demais, como, por exemplo, as utilitárias. Sobre estas esperam maior suporte pedagógico, melhor explicação de liçôes. No que diz respeito à relação com a figura de autoridade, em casa fazem de tudo para driblar os pais, e na escola utilizam estratégias para escapar da autoridade do professor. Às vezes demonstram o desejo de maior autonomia, noutras não: apresentam ambivalência quanto à autonomia, até porque não gostariam de assumir mais responsabilidades.

Sobre o conteúdo da educação, na escola eles sublinham a importância dos conteúdos com relação à sua utilidade no futuro, muitos aparecem sensíveis aos valores morais e sociais do programa. Quanto ao contexto familiar, salientam as mesmas dimensôes, regras sociais, porém, priorizam os saberes práticos, tais como: saber cozinhar, lavar, passar, cuidar das plantas etc. Com relação a seu futuro, as crianças se inquietam com ele muito cedo e esperam que a escola as ajude a conseguir um emprego. O papel desempenhado pelos pais aparece como mais amplo do que o da escola, além disso, eles se constituem como referências ou modelos - embora às vezes contramodelos. Elas desejam encontrar seu próprio lugar na sociedade através de uma profissão. Com relação à construção da identidade, "sua identidade se constrói em grande parte interpretando a imagem que seus camaradas têm delas" (MONTANDON, 1997, p. 227). Os adultos, pais e professores nem sempre discutem com elas as questôes fundamentais e os professores náo lhes informam a respeito das finalidades da instituição. As crianças são conscientes da construção de sua identidade. O sentido que eles dáo a suas experiências educativas decorre dos tipos de relação estabelecidos com a família, com a escola e da construção particular que fazem dos seus vividos e das suas experiências. Esses seres atuais constituem a infância.

No que diz respeito à experiência de autonomia, segundo pesquisa mencionada, Montandon e Longchamp (2007) investigaram 387 crianças de 10-12 anos, incluindo pais e professores na pesquisa. Por autonomia os autores entendem como "a capacidade e o poder da pessoa de governar-se, de tomar decisóes que lhe concernem" (MONTANDON; LONGCHAMP, 2007, p. 108).

Montandon e Longchamp (2007) especificam as seguintes dimensôes da autonomia, a saber: o plano reflexivo; o relacional; o de ação, do sentido prático e o 
identitário, da apresentação de si. Sendo assim, é neste último que as crianças demonstraram autonomia. Vale salientar que a autonomia identitária, da apresentação de si, estaria associada ao estatuto da criança de hoje: "Sob uma forte responsabilidade das instituiçôes, resta-lhes pouco espaço de liberdade. Os vestuários, o look, a música, os aparelhos eletrônicos se torna assim um espelho da liberdade" (MONTANDON; LONGCHAMP, 2007, p. 109). Em pesquisa realizada por Valença (2010) sobre valores cultural-estéticos predominantes em crianças catarinenses, também ficou evidenciado, entre 1.200 crianças pesquisadas, uma autonomia nesse mesmo plano.

Dessa forma, como as crianças representam sua autonomia? Que estratégias utilizam para alcançá-la? Os resultados da investigação de Montandon e Longchamp (2007) apontaram o seguinte: elas desconhecem o significado do termo, e entre as que conheciam o vocábulo verificou-se que as do meio operário possuem maior autonomia "prática" do que as demais (ser capaz de se virar sozinha), porém, elas participam menos das decisóes concernentes à escolha de cursos feitos fora da escola. As crianças filhas de famílias monoparentais e recompostas apresentam maior autonomia nos dois planos: prático e decisório. A ideia que têm de sua própria autonomia e o lugar da autonomia, entre outras qualidades, estão relacionados à escolha dos seus amigos (ter opinióes, decidir sobre suas roupas, filmes da televisão). A maioria sente-se capaz de lembrar-se de fazer suas tarefas escolares e uma minoria demonstra dificuldade em relação à gastar um valor maior de dinheiro ou mesmo de saber com quem gostaria de se parecer quando crescer. As atitudes das crianças ficaram em três planos: cognitivo (opinióes), afetivo (escolha de amigos) e identitário (escolha de estilo, de roupa). Geralmente expressaramse como tendo mais autonomia do que pensam os seus pais. Quanto à atitude em relação à autonomia, qualidades que desejariam ter quando crescessem, mostraram a autorregulação (atitude de definir objetivos para si mesmo), a acomodação (capacidade de se curvar às demandas e imposiçôes do ambiente social), e a cooperação (atitude de inventar, de imaginar, de ter ideais). Pragmática e sábia, a população pesquisada escolheu qualidades muito importantes: confiar em si mesma, ser bem educada, polida, hábil, se virar, trabalhadora e sociável. Porém, realistas, apontam que é necessário saber curvar-se às imposiçốes sociais. Entendem que vale mais a pena saber cooperar do que desenvolver sua autonomia/independência. Portanto, pensam que é melhor ser acomodada, sociável e só depois se autorregular.

Os alunos das escolas tradicionais resistem mais em aceitar as ordens dos professores. Também entre as crianças mais ricas o controle dos professores é menos aceito. Os meninos afirmam aceitar mais as exigências dos professores que as meninas. As crianças disseram ter mais experiência de autonomia em casa do que na escola. Quando os pais exercem controle maior, as crianças reagem tentando discutir, 
principalmente quando se trata de saída com colegas/amigos, ou da gestão do dinheiro da mesada. Montandon e Longchamp (2007, p. 120) concluem que a experiência de autonomia entre crianças "é globalmente forte quando os pais têm um estilo de educação contratual (no qual as crianças participam das decisões) e mais fraco quando eles apresentam estilo estatutário - no qual as crianças devem assumir seu estatuto de criança".

Ainda sobre autonomia, Corsaro (2011) pronuncia-se com relação à autonomia conceitual das crianças e da infância, que, como outros autores da sociologia infantil, tem trabalhos concentrados nelas como unidades básicas de pesquisa. Assim, elas se destacaram de outras unidades, tais como família e escola, passando a ser o foco de atenção. Isso já é considerado um avanço, o que não quer dizer que sendo elas colocadas como foco se excluam dos estudos as relaçóes entre elas e o meios/instituiçóes que frequentam.

Ademais, o autor refere-se à importância da autonomia, do eu e da identidade, em cultura de pares pré-adolescentes (de 7 a 13 anos). Tais comportamentos têm como precedentes as tentativas das crianças menores de controlarem suas próprias vidas, de se oporem e discutirem entre pares. Conflitos gerados no interior das culturas de pares demonstram que as crianças buscam se fazer respeitar, e que possuem um nível diferenciado de desenvolvimento individual e a demonstração de si. No entanto, é na pré-adolescência que elas demonstram a habilidade "de refletir sobre os sentidos de seus mundos em mudança e de avaliá-los durante as conversas umas com as outras e com os adultos" (CORSARO, 2011, p. 249). Assim, passam a se conscientizar de si mesmos e a reconhecer que afetam e são afetados pelos adultos, isto é, que exercem um certo nível de autonomia e liberdade.

\section{Sobre educação humanística e liberdade}

As relações educacionais vêm sendo frequentemente discutidas, quer sejam aquelas entre pais-filhos, quer entre professores-alunos. Elas se alteram com o passar dos tempos e acompanham as transformaçóes ocorridas nas representaçôes do homem e da infância. Os educadores oscilam na busca de estilos educativos adequados às crianças e seus comportamentos têm variado das puniçóes físicas, que a extremo levam à morte, às violências morais/psicológicas, e alguns ainda assumem uma postura de omissão ou do laisser faire, em que predomina a falta de regras e de limites.

$\mathrm{Na}$ busca da humanização da educação, alguns períodos da história da humanidade deixaram suas marcas. Foi o que aconteceu, por exemplo, com o Renascimento: o humanismo renascentista dava maior importância à razão humana do 
que à revelação divina. Essa nova representação humana enfatizava sua dignidade com o direito do uso de sua liberdade. O homem desse pré-humanismo, segundo Renaut (2002, p. 159), "se fixa, ele próprio, livremente seu lugar (tal é sua dignidade própria) mas não o faz senão no seio desta hierarquia dos seres e das formas que preexiste a sua escolha". O autor menciona ainda que Pic de La Mirondele teria alertado os homens quanto à escolha que fariam entre as que lhes foram disponibilizadas, refere-se, então, aos limites da liberdade que, em última instância, ressaltava a dependência do homem ao cosmos. Porém, entre Pic e Rousseau, três séculos adiante, a mudança foi grande, pois agora a liberdade "não encontra mais seus fins e seus valores em termos já prefixados, mas que ela aparece plenamente como sendo sua própria fonte" (RENAUT, 2002, p. 159). Em Rousseau, a redefinição da humanidade do homem foi posta em termos "de perfectibilidade e de liberdade" (RENAUT, 2002, p. 239).

Séculos se passaram até a admissão da criança como um ser destinado à liberdade. Ora recusada, ora admitida, a liberdade da criança estará sempre submissa aos poderes dos adultos. Portanto, em que medida estaria em causa a liberdade da criança na educação? Nos tempos atuais não parece mais aceitável desconhecer os direitos da infância, promulgados juridicamente, à medida que as sociedades democráticas estão fundadas nos valores da igualdade e da liberdade entre os seres humanos. Mas isso, de longe, estaria sendo suficiente, pois não faltam exemplos de crianças agredidas e mortas, inclusive pelos pais. Maltratadas, subjugadas, sujeitas às perversões de adultos, as crianças são encaminhadas para Casa Lar ou equivalentes. Para tanto, pergunta-se: como transformar esse estado de coisas? De que vale a proibição da palmada, a não ser, em muitas situaçóes, para colocar os holofotes em celebridades? Como confrontar os poderes a ponto de desmantelá-los estruturalmente e conseguir uma mudança social verdadeiramente comprometida com uma estruturação adequada/humanizada em que sejam respeitadas as diferenças/diversidade que compóem o cotidiano? Poder-se-ia considerar a sociedade atual como sendo democrática?

Se a criança moderna é considerada um sujeito e, como tal, um sujeito de direitos, ela não pode ser educada sem se levar em conta essa realidade. Por conseguinte, o adestramento da criança é inaceitável. Além da crueldade disciplinar, vez que isso é contraditório com a noção mesma de sujeito/liberdade, não se pode negar o fato de que ela é um ser humano. E todos os homens nascem e permanecem iguais em direitos, afirma a declaraçáo dos direitos do homem, que foi reforçada pela Assembleia Geral das Naçôes Unidas, em 20 de novembro de 1989. Pensar no outro como igual traz à baila a questáo da alteridade da criança. Sendo assim, a pergunta volta: como transpor da política à educação esses princípios? Parece que discutindo e colocando em cheque as 
concepçôes de autoridade e de hierarquia, mas também mudando as relaçôes face aos direitos das crianças no sentido de participação delas: ouvi-las, assimilar o que elas têm a dizer, possibilitar que façam parte das decisóes que lhes dizem respeito, ou seja, fazendo a transposição desses princípios e valores da política à educação.

\section{À guisa de conclusão}

Considerar a criança como tendo "uma essência diferente, não responsável, um ser incompleto que tem que aprender tudo com o adulto e que deve se adaptar aos projetos dos adultos, náo é a mesma coisa que pensar que ela é capaz de raciocinar, ter responsabilidades, ter direitos e deveres" (MONTANDON, 1997, p. 19). O educador precisa considerá-la como sendo uma construçáo nova, o que não significa que ela seja uma cópia fiel dos adultos. Isso implica, necessariamente, admitir que ela é sujeito e que a relação educativa é uma relação de reciprocidade.

Montandon (1997) pergunta-se a respeito do que fazem as crianças daquilo que lhes ensinam os adultos, e acrescenta: o que fazem os adultos daquilo que aprendem com as crianças? Não estaria isso relacionado à afirmação de que as crianças podem interferir na cultura dos adultos? Por que permanece tão difícil transformar algumas atitudes dos adultos com relaçáo a elas? $\mathrm{O}$ adulto precisa abdicar do centro de atenção em que se coloca, ser flexível às mudanças face à essa "nova criança", que é na realidade a "criança-criança"!

$\mathrm{O}$ que dizem os autores e o que expressaram as crianças pesquisadas por Montandon (1997, 2005, 2006) e Montandon e Longchamp (2007) parece não deixar dúvidas quanto ao rumo da educação: há efetivamente a necessidade de uma figura de autoridade, um desejo de autonomia/liberdade, de igualdade de direitos, mas diferentes comportamentos entre os dois seres em relação. Uma convivência saudável, equilibrada, exige do educador uma capacidade crítica associada ao desejo de viver com, conviver. As práticas que encorajam a autonomia "são exigentes para o indivíduo e podem ter um efeito desestabilizador sobre as crianças e seus pais" (MONTANDON, 2005, p. 494), o que não as invalida. São os pais, mais que os professores, de acordo com os resultados das pesquisas de Montandon, supramencionadas, que têm o privilégio de favorecer a autonomia das crianças, dando-lhes responsabilidade, exemplos, conselhos. No entanto, é bom náo perder de vista que o desejo de autonomia das crianças apareceu com uma forte carga de ambivalência... Crescer não é fácil!

Face à tantas interrogações é necessário não esquecer que:

[...] a educação é também onde decidimos se amamos as crianças o bastante para não expulsá-las de nosso mundo e 
abandoná-las a seus próprios recursos, e tampouco arrancar de suas mãos a oportunidade de empreender alguma coisa nova e imprevista por nós, preparando-as em vez disso com antecedência para a tarefa de renovar um mundo comum. (ARENDT, 1997, p. 247).

\section{REFERÊNCIAS}

AMORIM, Marília. O pesquisador e seu outro: Bakthin nas ciências humanas. São Paulo: Musa, 2001.

ARENDT, Hannah. Entre o passado e o futuro. 4. ed. São Paulo: Perspectiva, 1997. CORSARO, William A. Sociologia da Infância. Tradução de Lia Gabriele Regius Reis. Porto Alegre: Artmed, 2011.

FOUCAULT, Michel. Vigiar e punir: nascimento das prisôes. Tradução de Raquel Ramalhete. 35. ed. Petrópolis, RJ: Vozes, 2008.

LAUWE, Marie-José Chombart de. Enfant en jeu: les pratiques des enfants durant leur temps libre en fonction des types d'environnement. Paris: CNRS, 1976.

MIALARET, Gaston. Ciências da educação: aspectos históricos, problemas epistemológicos. Tradução de Eduardo Brandão. São Paulo: WMF Martins Fontes, 2013. (Coleção Biblioteca Pedagógica).

MONTANDON, Cléopâtre. L'éducation du point de vue des enfants. Paris: Harmattan, 1997.

MONTANDON, Cléopâtre. L'éducation du point de vue des enfants. Paris: Harmattan, 2004.

MONTANDON, Cléopâtre. As práticas educativas e a experiência das crianças. Educação \& Sociedade, Campinas, SP, v. 26, n. 91, p. 485-507, maio/ago. 2005.

MONTANDON, Cléopâtre. De l'étude de la socialisation des enfants à la sociologie de l'enfance: necessité au ilusion épistemologique? In: SIROTA, Régine (Org.). Élements pour une sociologie de l'enfance. Rennes: PUR, 2006. p. 41-50.

MONTANDON, Cléopâtre; LONGCHAMP, Philippe. Você disse autonomia? Uma breve percepção da experiência das crianças. Perspectiva, Florianópolis, SC, v. 25, n. 1, p. 105-125, jan./jun. 2007.

RENAUT, Alain. La liberation des enfants: contribution philosophique à une histoire de l'enfance. Calmann-Lévy: Bayard, 2002. 
VALENÇA, Vera Lúcia Chacon. Crianças de ascendência ucraniana: valores estético-culturais predominantes. Revista Percursos, Florianópolis, SC, v. 1, n. 1, p. 107-116, 2010. 


\section{Philosophical and sociological contributions on childhood}

\begin{abstract}
The central core of this article is to be found in some philosophical and sociological contributions on the history of childhood and its repercussions on educational relationships. A theoretical revision of the childhood history led to a childhood of exclusion, abandoned, without affection in ancient times, and later on, in modern times, resulted in a childhood constituted by "another child", with recognised legal rights. However, this equal, but different "other" and the contemporary childhood represented by "another child" is different, but has equal rights. So, the challenge for current educators consists of knowing how to relate with paradoxical alternating recognition of the different childhood, but with equal rights, exercising an horizontal hierarchy that enables the construction of identity and the search of the children's autonomy .
\end{abstract}

Keywords: Childhood. Theoretical contributions. Educational repercussions.

\section{Contribuciones filosóficas y sociológicas acerca de la niñez}

\section{Resumen}

El hilo conductor del presente artículo se encuentra en algunas contribuciones filosóficas y sociológicas acerca de la historia de la infancia y sus repercusiones en las relaciones educativas. Una revisión teórica acerca de la historia de la infancia mostro una concepción, en la antigüedad, una infancia excluida, abandonada, sin afecto; posteriormente, en la modernidad, una infancia constituida por un "otro - niño" con derechos jurídicos reconocidos, por lo tanto un "otro" igual, pero diferente; es la niñez contemporánea representada por un "otro - niño" diferente, pero con igualdad de derechos. De esta forma, el desafío para los actuales educadores consiste en saber relacionarse con la alteridad paradójica del niño, diferente e igual en derechos, ejerciendo una jerarquía horizontal que posibilite la construcción de la identidad y la búsqueda de autonomía en la infancia.

Palabras claves: Infancia. Contribuciones teóricas. Repercusiones educativas. 


\section{Vera Lúcia Chacon Valença}

E-mail:veravalenca@uol.com.br

Recebido em: 11/09/2014 Aprovado em: 08/12/2014 
